\title{
The Population Distribution of Al-Anbar Province Using Quantitative Methods in Geographic Information System for 2019
}

\author{
Khalid Ibrahim Hussein Al-Easawi, Qysser Abdullah Ahmed Farhan Al-Duliemi* \\ Department of Geography, Faculty of Art, University of Anbar, Iraq \\ * qysser.abdullah@uoanbar.edu.iq
}

KEYWORDS: $\quad$ Maps, Distribution, The Symbols, Population, The Quality.

Crossref doi) https://doi.org/10.51345/.v32i4.386.g240

\begin{abstract}
:
The importance of population distribution study appears through its direct impact on various fields such as economy, social and political fields. The research aims to show the pictures of the distribution of population in Anbar Province for 2019 according to its administrative units, but differently from the distributions taken earlier. We will depend on the distribution in several quantitative methods using GIS through multiple quantitative maps to show the ability of digital programs to represent in more than one method for same data, as well as the possibility of modern technologies of achieving maps and conduct spatial analyze at the lowest time and cost. This is what we see in the preparation of population maps for the region research clarifying what are the quantitative maps and showing the steps of their production in GIS and the symbols used as well as using ARC GIS programs in all research stages such as the progress of geographic return and then multiple drawing operations with the establishment of a digital database. The search came out a set of different maps in terms of the way drawing and output.
\end{abstract}

\section{REFERENCES:}

Campbell, map use and analysis, 3, edition, hill Newark, p. 17- 172.

Jones, Christopher, geographical, information systems and computer cartography, London, Longman, $1998 . p 4$.

Henry M. Kendall, "Introduction to Geography", Harcourt, Newark, 1951, p: 317 


\section{توزيع سكان محافظة الأنبار باستخدام الطرق الكمية في نظم المعلومات الجغرافية لعام 2019}

م.م. خالد إبراهيم حسين العيساوي، أ.م.د. قيصر عبدالله احمد الدليمي

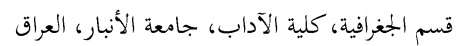

* qysser.abdullah@uoanbar.edu.iq

$$
\text { الكلمات المفناحية | الحرائط، التوزيع، الرموز، السكان، النوعية. }
$$

Crossref doi https://doi.org/10.51345/.v32i4.386.g240

\section{ملخص البحث:}

تأتي اهمية دراسة توزيع السكان من خلال تأثيرها المباشرة على مختلف الجمالات الاقتصادية والاجتماعية والسياسية، ويهدف

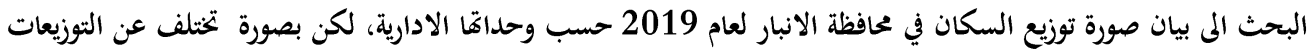

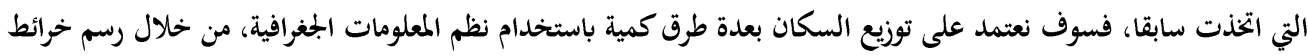

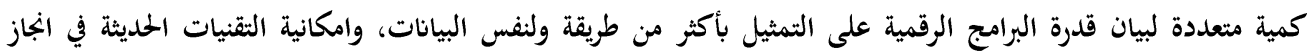

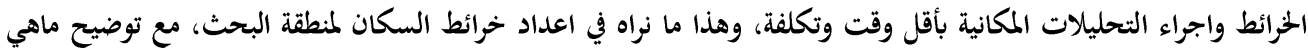

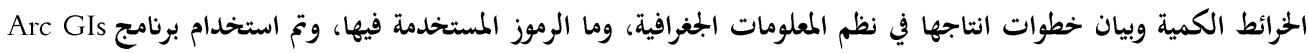

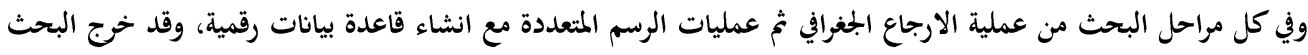
بمجموعة من الخرائط المختلفة من حيث طريقة الرسم والاخراج.

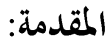

ان قدرة الجغرافي على فهم مشكلات دراسته البشرية يعتمد اساسا على مدى وفرة مادة احصائية دقيقة، وفي الوقت نفسة تمثيل تلك الاحصاءات والارقام بطرق كارتوكرافية جيدة (خرائط التوزيعات على سبيل المثال) التي تساعد الجغرافي على تلخيص ما تحتويه تلك الاحصاءات لبيان توزيع الظاهرات، فالنظر الى لئل خرائط التوزيعات تستطيع ان تغني القارئ عن دراسة الجداول الاحصائية التي غالبا ما تكون كثيرة التعقيد، وتتيح لنا نظم المعلومات الجغرافية عدة طرق كمية لتمثيل خرائط توزيع الظواهر البشرية وهذا ما تم اعتماده في هذا البحث في انتاج خرائط توزيع سكان محافظة الانبار. مشكلة البحث وتكون صياغتها بشكل الاتي هل ان برامج نظم المعلومات الجغرافية لها القدرة على انتاج خرائط كمية بأكثر من طريقة ولنفس البيانات وبشكل واضح؟ فرضية البحث وهي ان برامج نظم المعلومات الجغرافية لديها القدرة الكبيرة في رسم هذه الخرائط لاسيما عند وجود مستخدم لديه الحخبرة العالية لاستخدام 
البرامج، وانتاج الخرائط الكمية، ولديه دراية بتوزيع الظاهرات الجغرافية. اما عن هدف البحث حيث يهدف

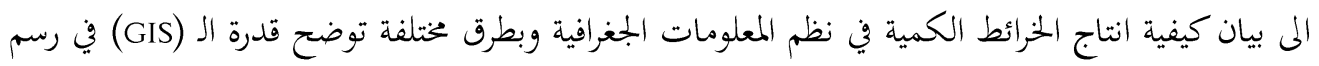

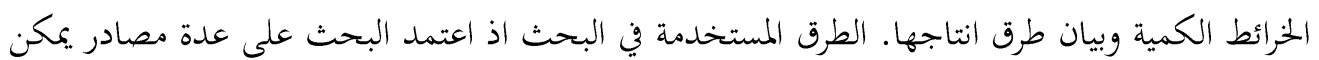
ايجازها بالآي:

\section{1 - 1 - 1 بريطة محافظة الانبار الادارية لعام 2019}

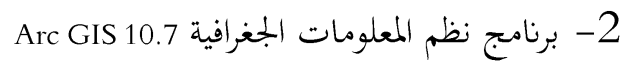

3- تقديرات السكان لمحافظة الانبار لعام 2019

حدود البحث والمتمثلة بحدود محافظة الانبار التي تقع في القسم الغربي من وسط العراق وللمحافظة حدود دولية وحدود ادارية حيث يحدها من الشمال محافظة نينوى ومن الشمال الشرقي محافظة صلاح الدين ومن لئن الشرق محافظتي بغداد وكربلاء، ويحدها من الجنوب والجنوب الغربي المملكة العربية السعودية، وفي الجنوب

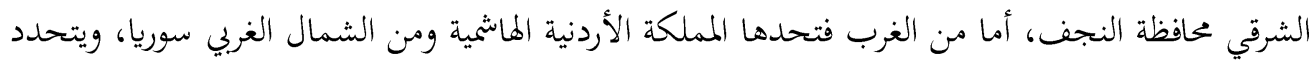

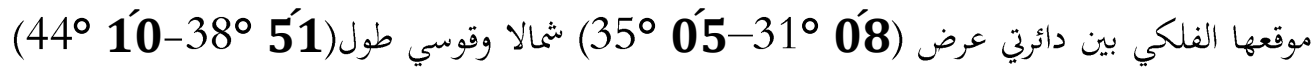

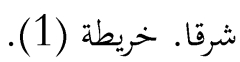

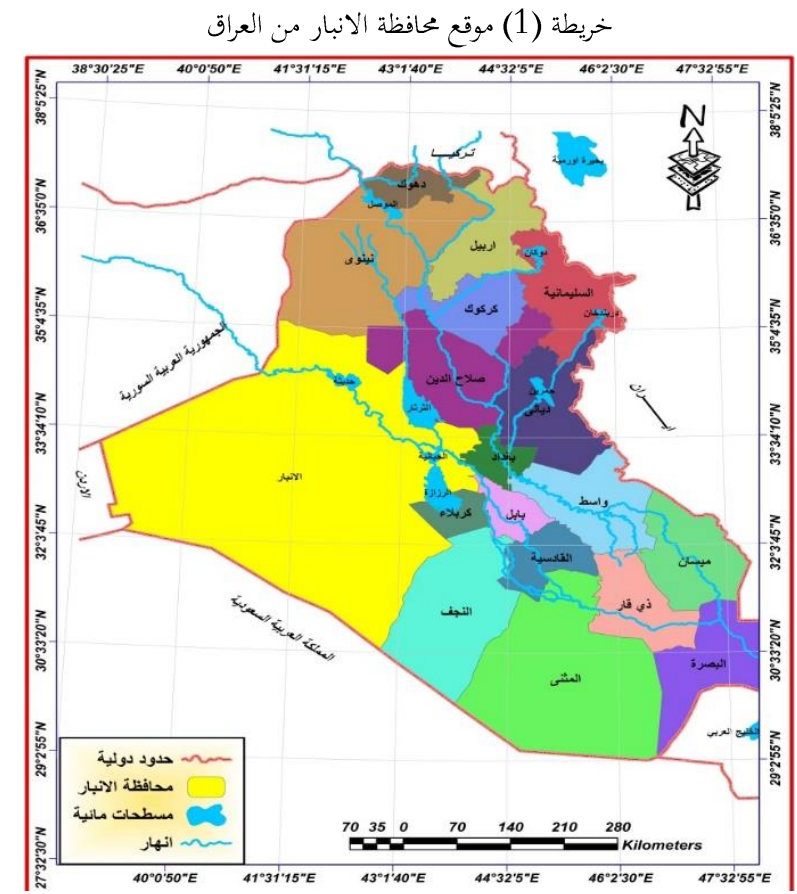

المصدر: جمهورية العراق، وزارة الموارد المائية، مديرية المساحة العامة، خريطة العراق الادارية، لعام 2015، مقياس 1000000/1 
اما بالنسبة للمساحة فتشكل محافظة الأنبار مساحة واسعة من العراق فهي أكبر المحافظات العراقية حيث تبلغ مساحتها (138288)كم² مشكلة نسبة (1,831\%) من مساحة العراق البالغة (435052) كم 2 وتتكون المحافظة اداريا من عشرة أقضية(1) وهي (الرمادي، هيت، الفلوجة، حديثة، عنه، راوه، الرطبة، القائم، الحبانية، العامرية) خريطة (2).

خريطة (2) اقضية محافظة الانبار حسب عام 2019

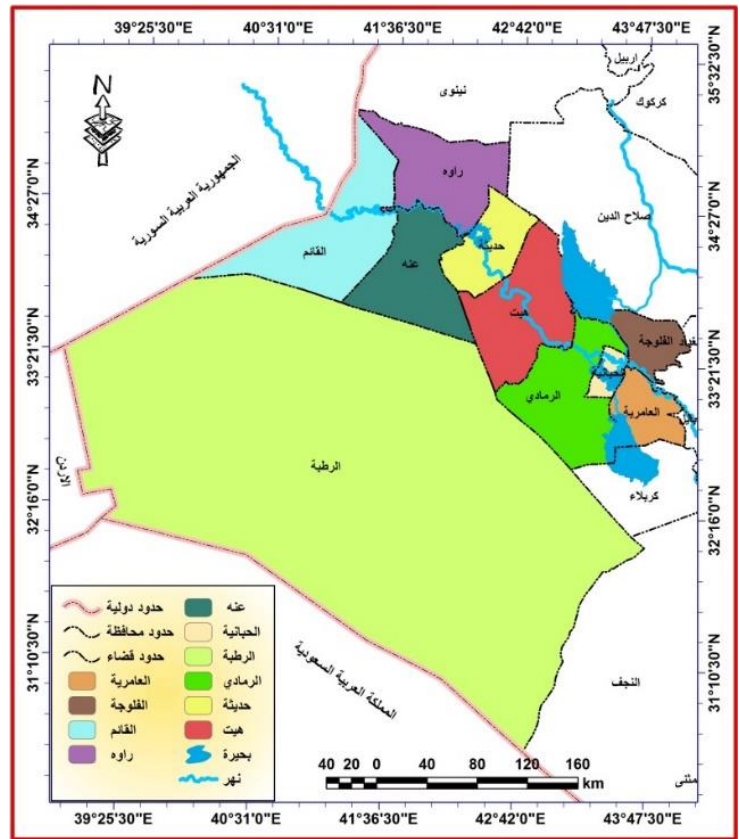

المصدر: جمهورية العراق، وزارة الموارد المائية، مديرية المساحة العامة، خريطة الانبار الادارية، لعام 2015، مقياس 1000000/1

\section{1 : تعريف خرائط التوزيعات}

هي الخرائط التي تستخدم طرق التمثيل الكاراتوكرافي لتوضيح العلاقات المكانية بين الظواهر الموزعة على الخرائط، مما يعطي صورة حقيقية للمشكلات الاقتصادية والاجتماعية، ويوفر سهولة في التحليل العلمي أي ان خرائط التوزيعات واسعة في شموليتها محا يجعل أي خريطة هي عبارة عن خريطة توزيع اذ من المستحيل توضيح الموقع النسبي بدون اظهار التوزيع، لذا فان أي ظاهرة جغرافية طبيعية او بشرية يمكن ان توزع ضمن خرطة التوزيع(2). 2: انواع خرائط التوزيعات هناك طريقتين لتمثيل خرائط التوزيعات وهما: 
2-1-2 الخرائط الكمية: يعتمد رسم هذه الخرائط على البيانات والقيم الاحصائية التي تمثل كمية الظاهرة او كثافتها، اذ تستعمل رموز كمية لإظهار هذه التوزيعات التي ترتبط بمكان الظاهرة الجغرافية وتعتمد هذه الخرائط على عدة رموز منها رموز نسبية وعددية التي تبين توزيع السكان لمنطقة معينة والخريطة الكمية تقوم على اساس توضيح الموقع النسبي للظواهر الجغرافية ومنها توزيع كثافة السكان(3).

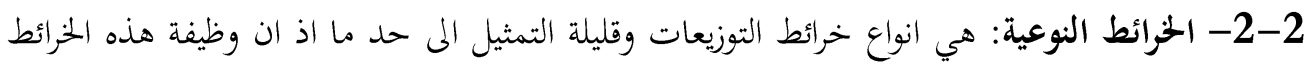

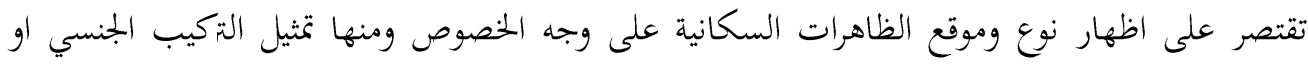
الوظيفي او اللغة والديانة للسكان، بغض النظر عن الكميات والاعداد التي تمثلها كما اها هتم بإبراز الحقائق الجغرافية دون الاعتماد على المصادر الاحصائية(4). والجدير بالذكر انهي انه تم استخدام الطريقتين في تثثيل الخرائط لتوزيع السكان في منطقة البحث من خلال عدة طرق متمثلة بالتوزيع العددي والنسبي

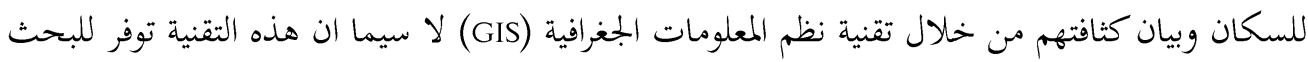
الجغرافي الامكانية والدقة في تمثيل خرائط التوزيعات. 3: الرموز المستخدمة في البحث هنالك عدة رموز تستخدم في رسم وتصميم الخرائط الكمية تعرف باسم طرق التمثيل الرمزي لتمثيل

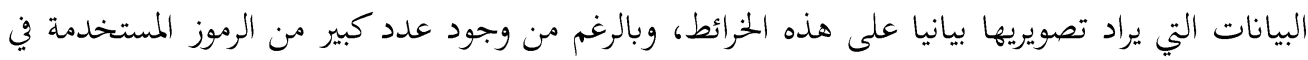

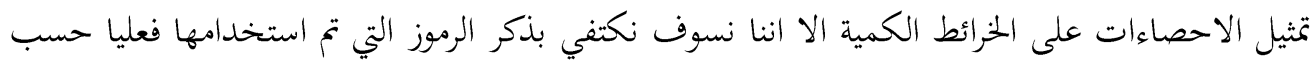
حاجة البحث وهي كما يأتي: Quantitative Location Symbols -3-1 Quantitative Cadastral Symbols -3-1

ان عملية تمثيل رموز الموضع في الخرائط الكمية يتم بإحدى الطريقتين الاتيتين(5). 3-1-1: الطريقة التي تقوم على اساس تكرار رمز نقطي منتظم الحجم معلوم القيمة ويمثل العدد الكلي

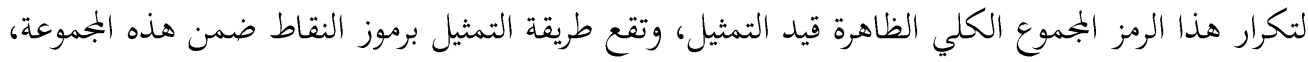

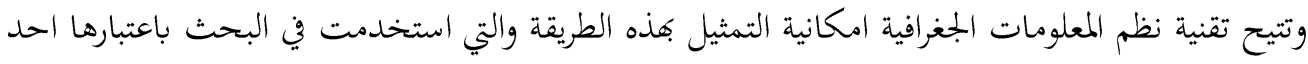

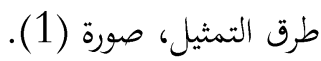


صورة (1) طريقة تمثيل النقاط (Dot density)

File Edit View Bookmarks Inset Selection Geoprocessing Customize Windows Help

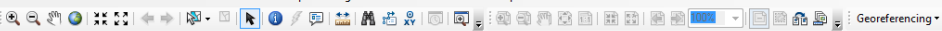

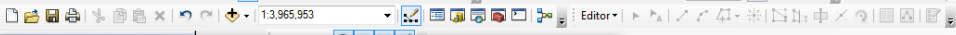

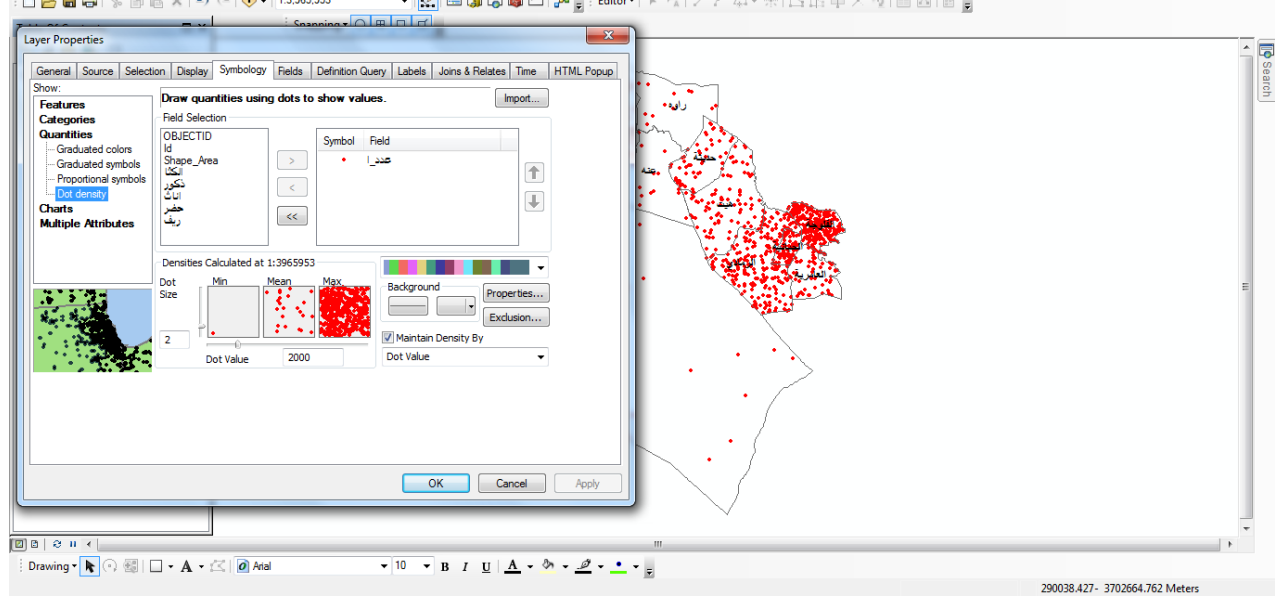

Arc GIS 10.7 المصدر: عمل الباحثان بالاعتماد على برنامج نظم المعلومات

3-1-2: الطريقة التي تعتمد على تمثيل بيانات الظاهرة برموز موضعية نسبية وهي رموز يتغير طوها او مساحتها او حجمها تغيرا نسبيا حسب تغير مقدار الكم الذي يمثله الرمز، مثل طريقة التمثيل برموز الخط والمساحة (الدائرة، المربع، المثلث). صورة (2).

صورة (2) طريقة تمثيل الدوائر (pie)

File Edit Vieiv Bookmarks Insert Selection Geoprocessing Customize Windows Hell

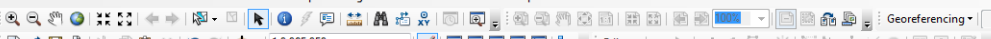

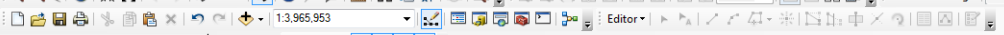

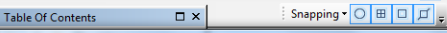

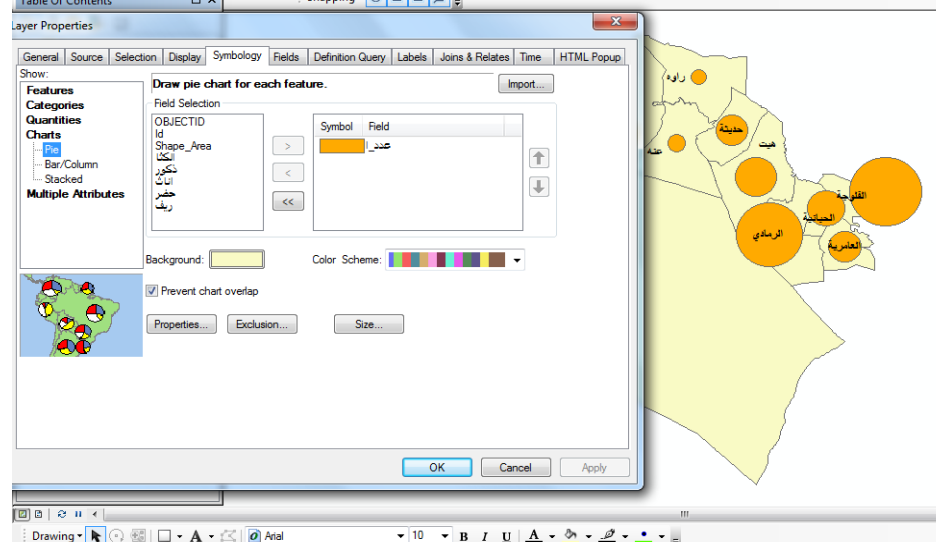

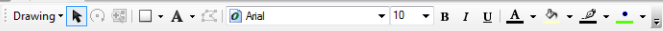

291087.754- 3757229.776 Meters

Arc GIS 10.7 المصدر: عمل الباحثان بالاعتماد على برنامج نظم المعلومات 


\section{3-2-3 رموز المساحة الكمية}

يعد التضليل النسبي من الوسائل والاساليب التي اخذ بعض الكارتوكرافيين في دراساهم وبحوثهم لأهما تساعد الوسائل الوصفية في عرض الظواهر الجغرافية بأسلوب علمي وكمي ودقيق، كما لاقت هذه الرموز اهمية وعناية نتيجة لما تقدمه من حلول في توزيع الظواهر . وطرائق تمثيلها هي:

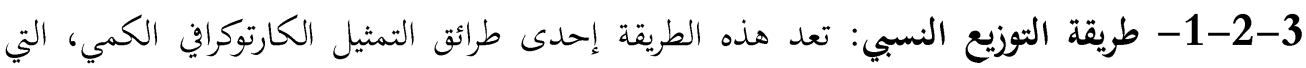

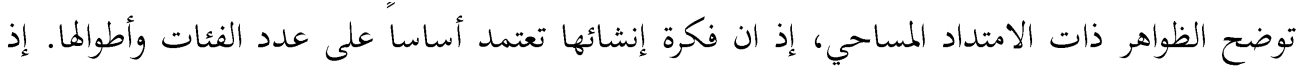
تسمح الفئات من خلال تدرجها باستعمال أنماط التضليل المتدرج الذي تعتمده اساسا في عملية التمثيل للظواهر وكذلك تستعمل الألوان بدلاً من أنماط التضليل، وتعد هذه الطريقة من الطرق الأكثر شيوعا في

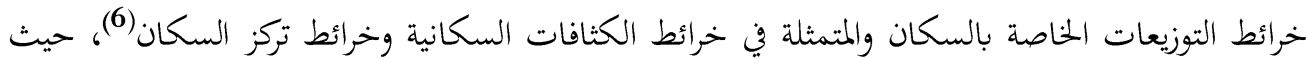
تم استخدام هذه الطريقة في تمثيل خرائط الكثافة العامة لسكان اقضية محافظة الانبار التي سوف يتم التطرق اليها لاحق . 3-2-2-2- طريقة خطوط التساوي: هي احدى طرق المساحة الكمية تتلخص باستخدام بعض انماط التضليل المتدرج (7)، لكن لم يتم استخدامها في تمثنل بيانات البحث لعدم الحاجة اليها. صورة (3).

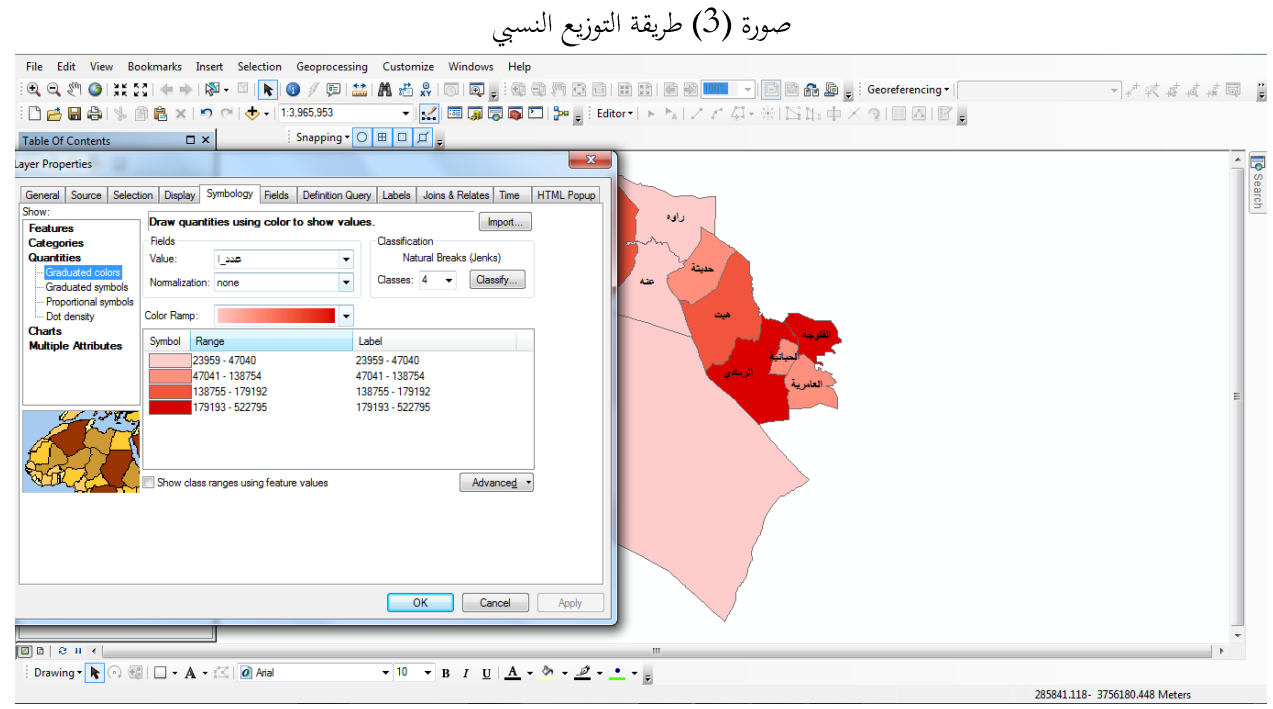

Arc GIS 10.7 المصدر : عمل الباحثان بالاعتماد على برنامج نظم المعلومات 


\section{4: انتاج خرائط توزيع السكان}

تمثلت هذه المرحلة بمجموعة من الخطوات العملية من خلال نظم المعلومات الجغرافية لإنتاج وتحليل توزيع

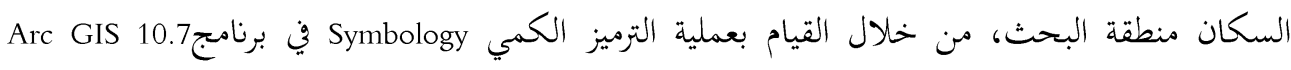
والتطبيق Arc map والتي تم من خلالها انتاج الخرائط الكمية للمحافظة بالاعتماد على جدول الخصائص Attribute Table الذي تم اعتماده لكل وحدة ادارية في المحافظة. صورة (4).

Attribute Table جدورة (4) عملية الترميز الكمي Symbology

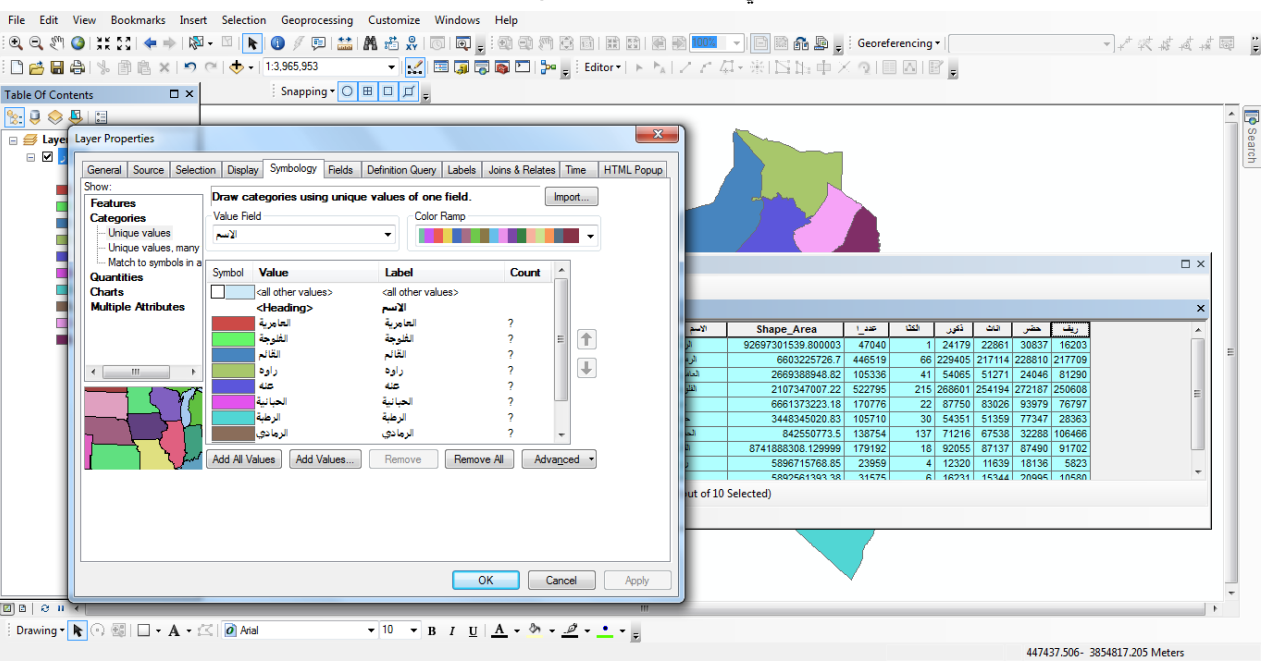

Arc GIS 10.7 المصدر : عمل الباحثان بالاعتماد على برنامج نظم المعلومات

\section{1-4-1 - توزيع السكان العددي}

يتحدد مفهوم التوزيع العددي للسكان بعدد أو حجم السكان الذين تم حصرهم في مكان معين، وخلال وقت معلوم. أي أن المفهوم يؤكد على العدد المطلق للسكان في أي منطقة من المناطق، وما يترتب عليها من مراتب دون إعطاء أهمية نسبية لمذا العدد بالنسبة إلى المنطقة أو الإقليم الذي يقع فيه(8). ويرتبط التوزيع العددي للسكان ارتباطا وثيقا بالخريطة، التي لا يمكن من دوفا فهم وتصور هذا التوزيع، وقد

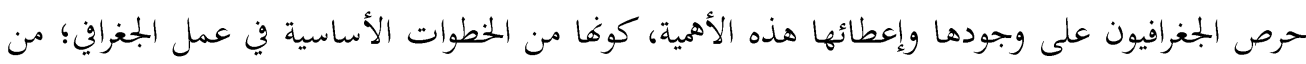
أجل تحليل الظواهر الجغرافية والسكانية التي يهتم بها لتسهيل عملية المقارنة واستخلاص النتائج(9).

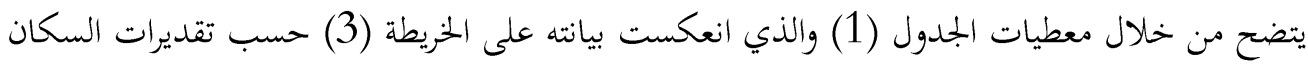
لعام 2019 ان هنالك تباين مكاني في توزيع السكان، ويتضح ان اجمالي عدد سكان محافظة الانبار 
(1771656) نسمة موزعة مكانيا على اقضية محافظة الانبار اذ جاء قضاء الفلوجة بأكبر حجم سكاني وهذا يعود الى الموقع الجغرافي الحيوي الذي يتمتع به القضاء فضلا عن وجود مركز حضري كبير والمتمثل بمركز مدينة الفلوجة، وفي المرتبة الثانية جاء قضاء الرمادي والذي يمثل مركز محافظة الانبار، بينما جاء في في بهري المرتبة الاخيرة قضاء راوه.

\begin{tabular}{|c|c|c|}
\hline$\%$ & السكان & القضاء \\
\hline 25,2 & 446519 & الرمادي \\
\hline 9,6 & 170776 & هيت \\
\hline 29,5 & 522795 & الفلوجة \\
\hline 1,8 & 31575 & عنه \\
\hline 6 & 105710 & حديثة \\
\hline 2,7 & 47040 & الرطبة \\
\hline 10,1 & 179192 & القائم \\
\hline 1,3 & 23959 & راوه \\
\hline 7,8 & 138754 & الحبانية \\
\hline 5,9 & 105336 & العامرية \\
\hline 100 & 1771656 & الجموع \\
\hline
\end{tabular}

المصدر: جمهورية العراق، وزارة التخطيط والتعاون الانمائي، الجهاز المركزي للإحصاء وتكنلوجيا المعلومات، الجمموعة الاحصائية السنوية لعام 2019، جدول رقم 44، ص21. 


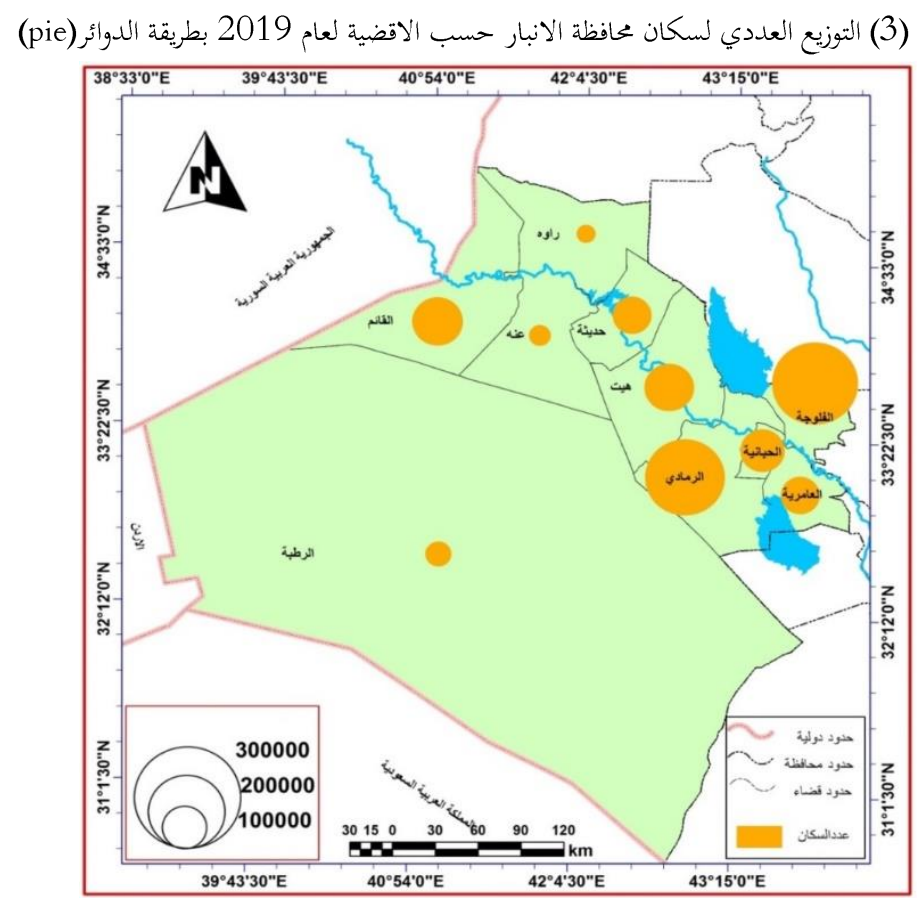

GIS 10.7 المصدر : بالاعتماد على جدول (1) وبرنامج نظم المعلومات الجغرافية

يتضح لنا من الخريطة (3، 4، 5، 6) ان جميعها تعطي توزيعا عدديا للسكان وحسب الاقضية التابعة للمحافظة، ولكن تباينت صيغة اخراج تلك الخرائط حيث اعتمد الباحثان في طريقة رسم الخريطة (3) على اعطاء حجم السكان الفعلي لكل قضاء أي ان حجم الدائرة يمثل حجم السكان وكما موضح في مفتاح الخريطة، املا الخريطة (4) رسمت بنفس طريقة الدوائر لكن باختلاف الرموز الا وهي المربعات وذلك لإعطاء توضيح عن قدرة البرنامج بالترميز بعدة اشكال حسب رغبة المستخدم. اما بالنسبة لخريطة (5) بالرغم من اعتماد نفس البيانات الخاصة بتوزيع السكان الا انه في هذه الخريطة كان للبرنامج دور اساسي بإعطاء قيمة واحدة التي يمثلها حجم المثلث في المفتاح الا وهي 300000 نسمة حجم المثلث.

وفيما يخص الخريطة (6) فقد رسمت بطريقة (Bar\Colum) طريقة الاعمدة المنفردة لإعطاء صورة اخرى للتوزيع العددي للسكان، وهي أحد انواع الرسوم البيانية (Charts) التي يوفرها البرنامج وهنا يمثل كل عامود عدد السكان في القضاء التي يقع فيها اما قيمة العمود فلا يمكن الاعتماد على النموذج الذي يعطيه البرنامج، وانما تم الاعتماد على الطريقة التي رسمها الباحث حيث يمكن ادراج في مفتاح الخريطة حجم العمود مقسم وحسب عدد السكان. 
خريطة (4) التوزيع العددي لسكان محافظة الانبار حسب الاقضية لعام 2019 بطريقة المربعات

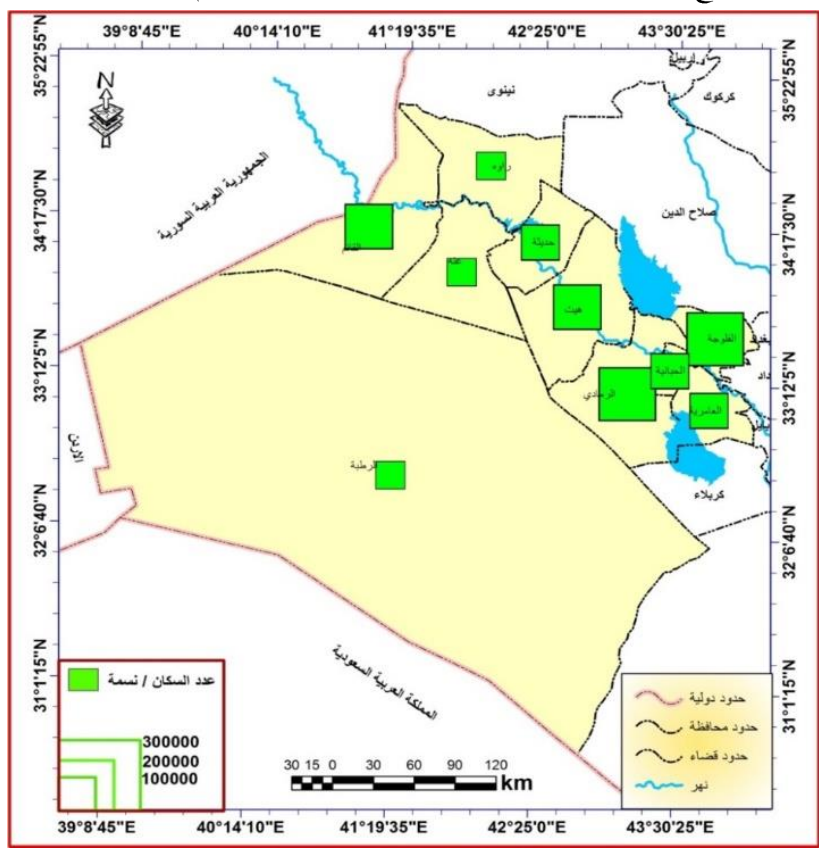

GIS 10.7 المصدر: بالاعتماد على جدول (1) وبرنامج نظم المعلومات الجغرافيةه

خريطة (5) التوزيع العددي لسكان محافظة الانبار حسب الاقضية لعام 2019 بطريقة المثلثات

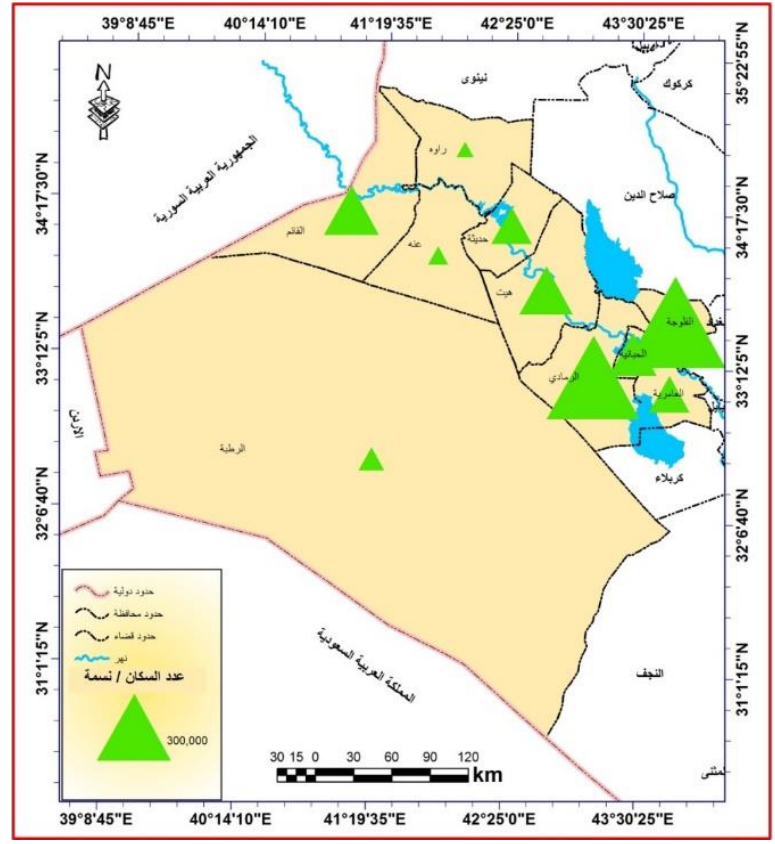

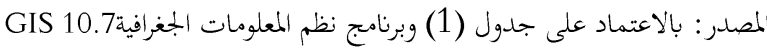




\section{2-4- توزيع السكان العددي حسب البيئة (ريف - حضر)}

إن توزيع السكان على أساس الحضر والريف، له أهمية بارزة في الدراسات السكانية، إذ يعكس العلاقة

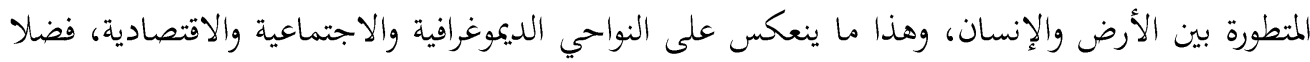

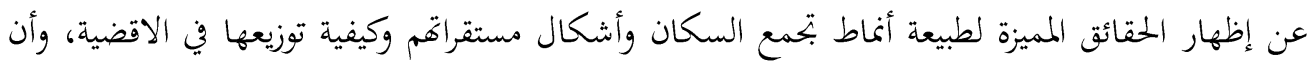

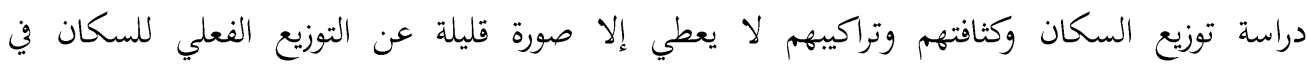
الاقضية(10)

خريطة (6) التوزيع العددي لسكان محافظة الانبار حسب الاقضية لعام 2019 بطريقة الاعمدة (Bara\Colum)

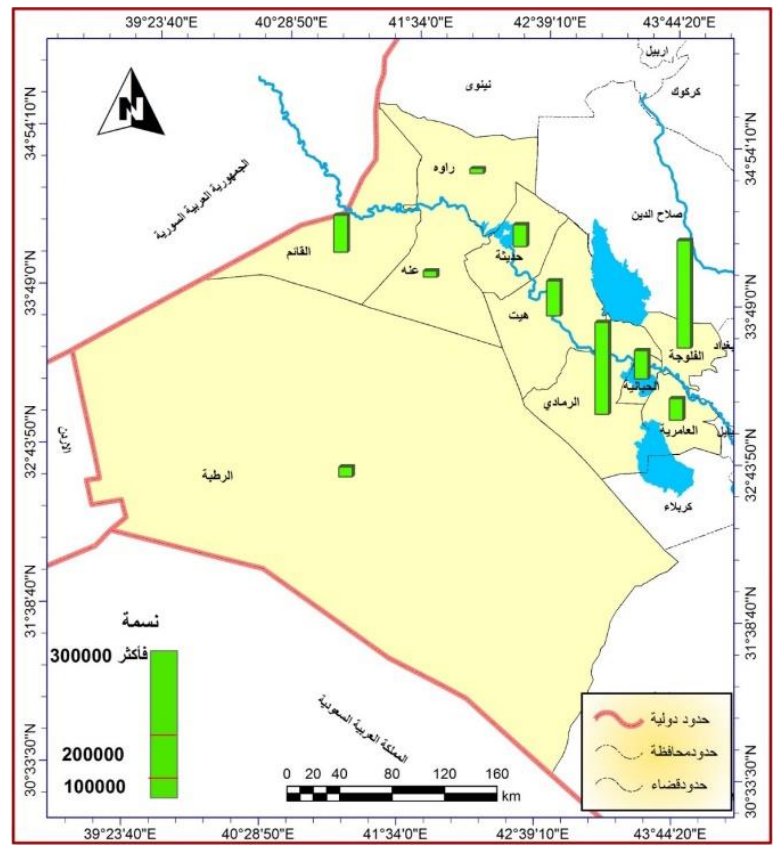

GIS 10.7 المصدر: بالاعتماد على جدول (1) وبرنامج نظم المعلومات الجغرافية

يتضح من خلال الجدول (2) والخريطة (7، 8) قدرة نظم المعلومات الجغرافية على انتاج خرائط متعددة ولنفس البيانات كما اهما لديها الامكانية في رسم خريطة التوزيع العددي والنسبي، وان هنالك تباين مكاني في توزيع سكان الريف والحضر في اقضية المحافظة حيث سجل قضاء راوه أكبر نسبة لسكان الحضر والتي بلغت (\%75,7) يلها قضاء حديثة وبنسبة (73,2\%)، بينما سجل قضاء العامرية اعلى نسبة لسكان الريف حيث بلغت (\%7,2\%) ويليه قضاء الحبانية وبنسبة (76,7\%). 


\begin{tabular}{|c|c|c|c|c|c|}
\hline بجموع & $\%$ & ريف & $\%$ & حضر & القضاء \\
\hline 446519 & 48,8 & 217709 & 51,2 & 228810 & الرمادي \\
\hline 170776 & 45 & 76797 & 55 & 93979 & هيت \\
\hline 522795 & 47,9 & 250608 & 52,1 & 272187 & الفلوجة \\
\hline 31575 & 33,5 & 10580 & 66,5 & 20995 & عنه \\
\hline 105710 & 26,8 & 28363 & 73,2 & 77347 & حديثة \\
\hline 47040 & 58,4 & 16203 & 41,6 & 30837 & الرطبة \\
\hline 179192 & 51,2 & 91702 & 48,8 & 87490 & القائم \\
\hline 23959 & 24,3 & 5823 & 75,7 & 18136 & راوه \\
\hline 138754 & 76,7 & 106466 & 23,3 & 32288 & الحبانيه \\
\hline 105336 & 77,2 & 81290 & 22,8 & 24046 & العامرية \\
\hline 1771656 & 50 & 885541 & 50 & 886115 & الجموع \\
\hline
\end{tabular}

لمصدر: جمهورية العراق، وزارة التخطيط والتعاون الانمائي، الجهاز المركزي للإحصاء وتكنلوجيا المعلومات، المجموعة الاحصائية السنوية

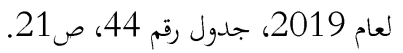

فيما يخص انتاج خرائط التوزيع النسبي والعددي البيئي (حضر ريف) تم انتاج خريطتين (7، 8) فقد تم

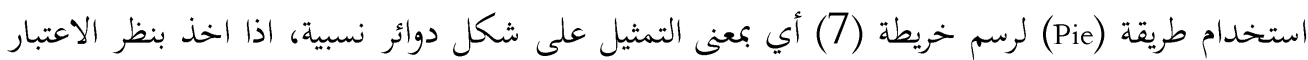
نسبة الحضر والريف فقط دون عددهم فقد تم استخدام الحنيار الاول في برنامج نظم المعلومات الذي هو ايعاز (Fixed size)، والذي يعني ان حجم الدوائر يكون ثابت في كل الاقضية والاختلاف هنا يكون داخل الدائرة وذلك حسب اختلاف نسبة السكان الحضر عن الريف في كل قضاء. 


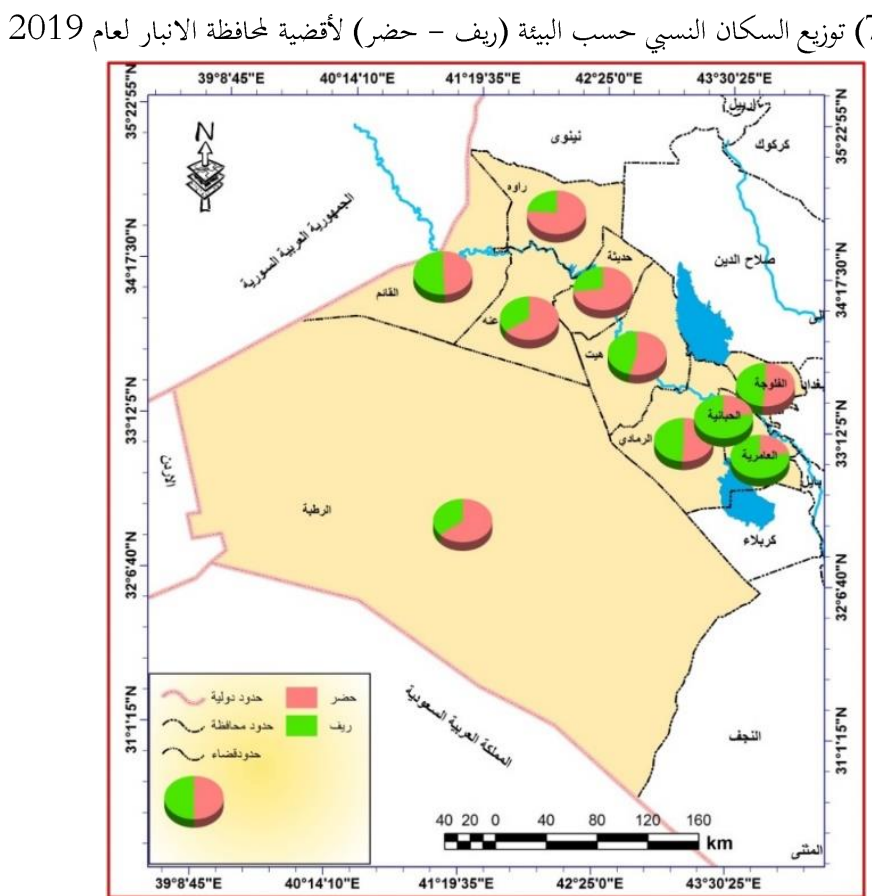

GIS 10.7 المصدر: بالاعتماد على جدول (2) وبرنامج نظم المعلومات الجغرافية

خريطة (8) توزيع السكان العددي حسب البيئة (ريف - حضر) لأقضية لمافظة الانبار لعام 2019

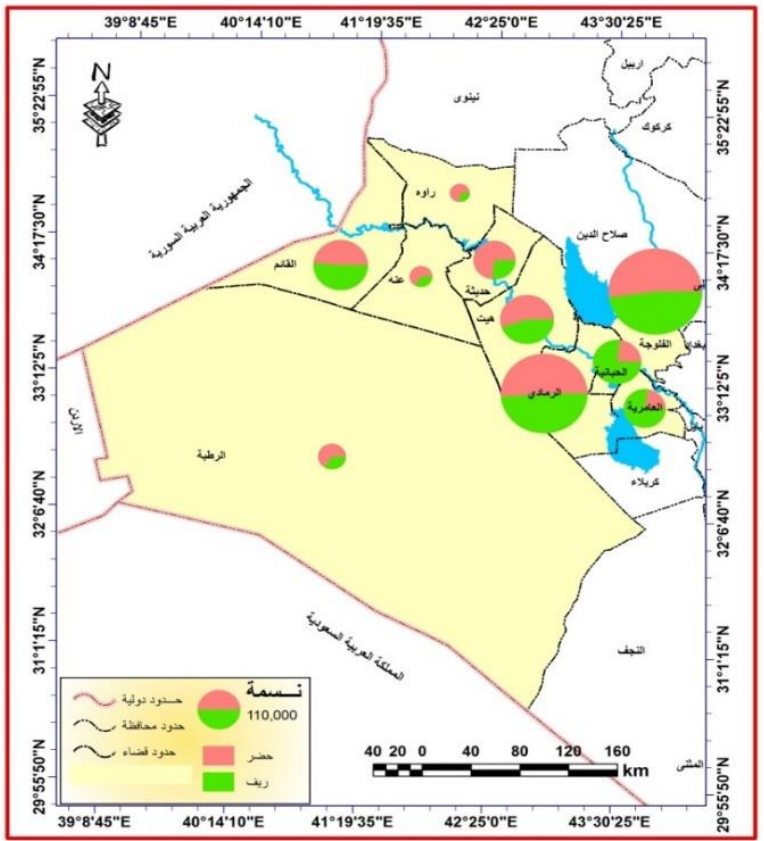

GIS 10.7 المصدر: بالاعتماد على جدول (2) وبرنامج نظم المعلومات الجغرافيةه 
وفيما يخص الخريطة (8) التي تبين التوزيع العددي للسكان حسب البيئة اذ تم فيها استخدام (Pie) أي التمثيل على شكل دوائر نسبية ولكن اخذ بنظر الاعتبار عدد السكان وليس نسبتهم من خلال اختيار

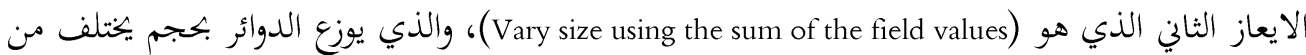
مكان الى اخر حسب اختلاف عدد السكان وايضا يعطينا نموذج يمكن ادراجه في المفتاح على اساسه نأخذ فكرة عن قيمة كل دائرة وكم يشكل الحضر والريف منها.

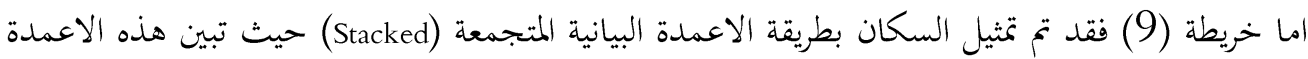
المتجمعة عدد السكان الحضر والريف في كل قضاء وهي طريقة اخرى توفرها نظم المعلومات الجغرافية.

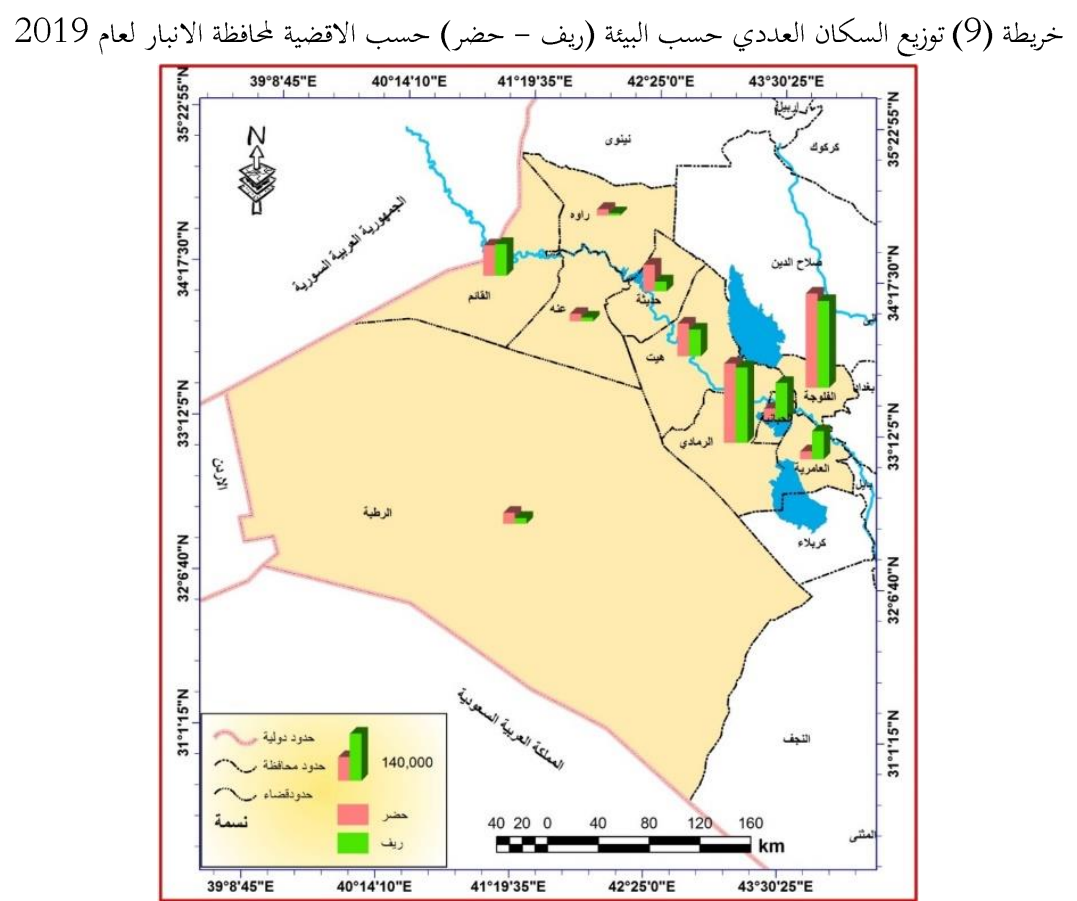

GIS 10.7 المصدر : بالاعتماد على جدول (2) وبرنامج نظم المعلومات الجغرافية

\section{4-3- توزيع السكان العددي حسب الجنس (ذكور- اناث)}

يقصد بالتركيب النوعي تقسيم السكان الى ذكور واناث حيث يعبر عن العلاقة بينهما عادة بما يعرف بنسبة النوع او الجنس، ويعد التركيب النوعي للسكان من الصفات الديموغرافية الأساسية التي تؤثر بطريق مباشرة

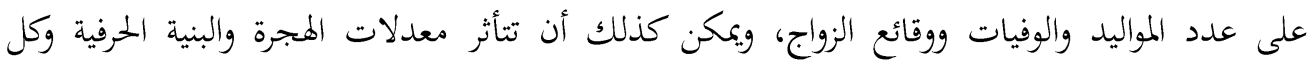
الصفات السكانية الأخرى بالنسبة العددية بين النوعين (ذكور وإناث). 
وتعد بيانات النوع ضرورة في حد ذاتا، كما اها هامة بالنسبة لتحليل غيرها من البيانات، فكون الفرد ذكرا

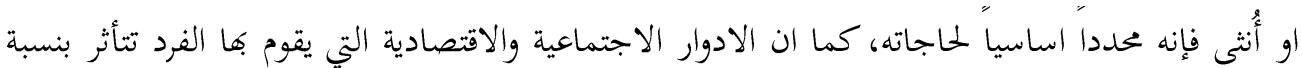
النوع، وهي تمثل معيارا للظروف الاجتماعية والاقتصادية السائدة في المنطقة، وهي أداة مفيدة في دراسة التباينات الجغرافية، وهي لها دور مؤثر في عدة عناصر ديموغرافية، مثل نمو السكان ومعدلات الزواج

والتركيب الاقتصادي وغيرها (11). يتضح من الجدول (3) ان هنالك تقارب كبير في نسب التوزيع للسكان حسب الجنس بين اقضية المحافظة،

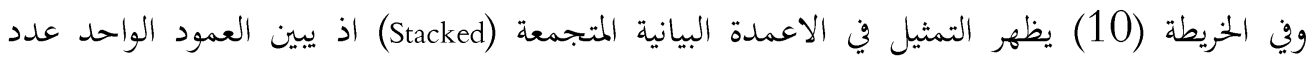
السكان في القضاء حسب الجنس (ذكور - اناث) جزء منه يمثل الذكور والجزء الاخر يمثل الاناث وهي احدى انواع الرسوم البيانية التي يوفرها البرنامج في التمثيل الكمي للبيانات.

جدول (3) توزيع السكان حسب الجنس (ذكور - اناث) حسب الاقضية في محافظة الانبار لعام 2019 ( 2019

\begin{tabular}{|c|c|c|c|c|c|}
\hline جموع & $\%$ & اناث & $\%$ & ذكور & القضاء \\
\hline 446519 & 48,7 & 217114 & 51,3 & 229405 & الرمادي \\
\hline 170776 & 48,6 & 83026 & 51,4 & 87750 & هيت \\
\hline 522795 & 48,7 & 254194 & 51,3 & 268601 & الفلوجة \\
\hline 31575 & 48,6 & 15344 & 51,4 & 16231 & عنه \\
\hline 105710 & 48,1 & 51359 & 51,9 & 54351 & حديثة \\
\hline 47040 & 48,6 & 22861 & 51,4 & 24179 & الرطبة \\
\hline 179192 & 48,7 & 87137 & 51,3 & 92055 & القائم \\
\hline 23959 & 48,6 & 11639 & 51,4 & 12320 & راوه \\
\hline 138754 & 48,7 & 67538 & 51,3 & 71216 & الحبانية \\
\hline 105336 & 48,7 & 51271 & 51,3 & 54065 & العامرية \\
\hline 1771656 & 48,6 & 861483 & 51,4 & 910173 & الجموع \\
\hline
\end{tabular}

المصدر: جمهورية العراق، وزارة التخطيط والتعاون الانمائي، الجهاز المركزي للإحصاء وتكنلوجيا المعلومات، الجموعة الاحصائية السنوية

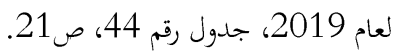




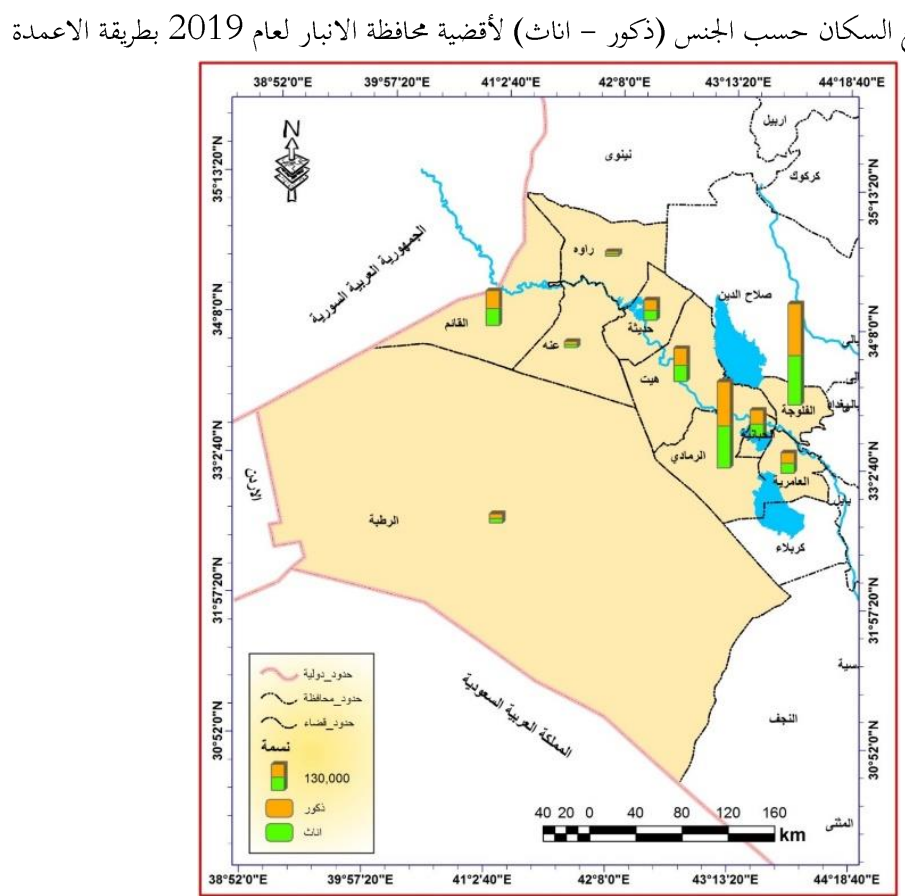

GIS 10.7 المصدر : بالاعتماد على جدول (3) وبرنامج نظم المعلومات الجغرافية

\section{4-4-4 توزيع الكثافة النسبية لسكان محافظة الانبار}

وهي العلاقة بين حجم السكان والمساحة التي يتكون منها القضاء، وتحتل الحقائق الديموغرافية المتعلقة بتوزيع السكان أهمية بالغة عند وضع السياسات السكانية الخناصة بالجوانب الاقتصادية والاجتماعية، التي تمدف إلى تطوير مختلف المناطق، وعليه فإن بعض الباحثين في الشؤون السكانية أخذوا يهتمون بتوزيع السكان؛ لذا أصبحت الحقائق المتعلقة بعدد السكان وتوزيعهم الجغرافي من بين العناصر الأساسية التي تدخل في تكوين عملهم وونهجهم في البحث (12). وبناء على ما تقدم، تعد خريطة توزيع السكان من أهم الخرائط في الدراسات الجلغرافية؛ لأها مرآة تنعكس عليها جميع العناصر الجغرافية، الطبيعية منها والبشرية، وبصورة متفاعلة(13). ويتضح من الجدول (4) والخريطة (11) وجود تباين مكاني في نسبة الكثافة العامة فيما بين اقضية المحافظة لذلك سوف يتم تقسيم الاقضية الى اربع مستويات حسب الكثافة العامة وكما يأتي: 
المستوى الاول: من 1 - 22 نسمة/ 1كم²: ويضم كل من الاقضية (الرطبة، وراوه، وعنه، وهيت) وهي اقل الاقضية من حيث الكثافة ويعود ذلك الى صغر الحجم السكاني مقابل المساحة الكبيرة للأقضية. المستوى الثاني: من 23 - 66 نسمة/كم²: ويضم كل من الاقضية (القائم، حديثة، العامرية، الرمادي)

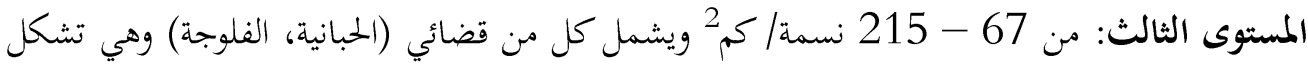
أكبر كثافة على مستوى المحافظة بسبب حجم السكان الكبير مع صغر المساحة فضلا عن المركز الحضري الكبير والمتمثل بمدينة الفلوجة.

جدول (4) توزيع السكان والمساحة والكثافة العامة لمافظة الانبار حسب الاقضية لعام 2019

\begin{tabular}{|c|c|c|c|c|c|}
\hline الكثافة & $\%$ & المساحة (2) & $\%$ & السكان (1) & القضاء \\
\hline 66 & 4,9 & 6733 & 25,2 & 446519 & الرمادي \\
\hline 22 & 5,6 & 7629 & 9,6 & 170776 & هيت \\
\hline 215 & 1,8 & 2428 & 29,5 & 522795 & الفلوجة \\
\hline 6 & 3,9 & 5274 & 1,8 & 31575 & عنه \\
\hline 30 & 3,2 & 4374 & 6 & 105710 & حديثة \\
\hline $\mathbf{0 , 5}$ & 66,4 & 91507 & 2,7 & 47040 & الرطبة \\
\hline 18 & 7, 3 & 9899 & 10,1 & 179192 & القائم \\
\hline 4 & 4,3 & 5725 & 1,3 & 23959 & راوه \\
\hline 137 & 0,7 & 1010 & 7,8 & 138754 & الحبانية \\
\hline 41 & 1,9 & 2587 & 5,9 & 105336 & العامية \\
\hline 13 & 100 & 137808 & 100 & 1771656 & الجموع \\
\hline
\end{tabular}

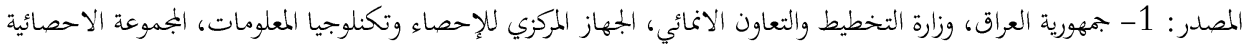

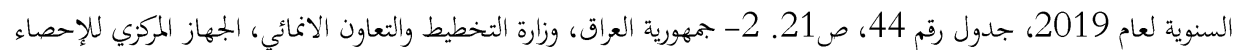

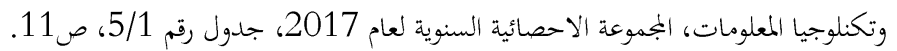

وتم انتاج خريطة (11) من خلال تقسيم عدد السكان على المساحة العامة لأقضية محافظة الانبار وبالنتيجة تم معرفة الكثافة العامة للسكان من خلال استخدام طريقة التدرج اللوني (Graduated colors) للتميز بين فئة واخرى. 
خريطة (11) الكثافة العامة لسكان اقضية محافظة الانبار لعام 2019

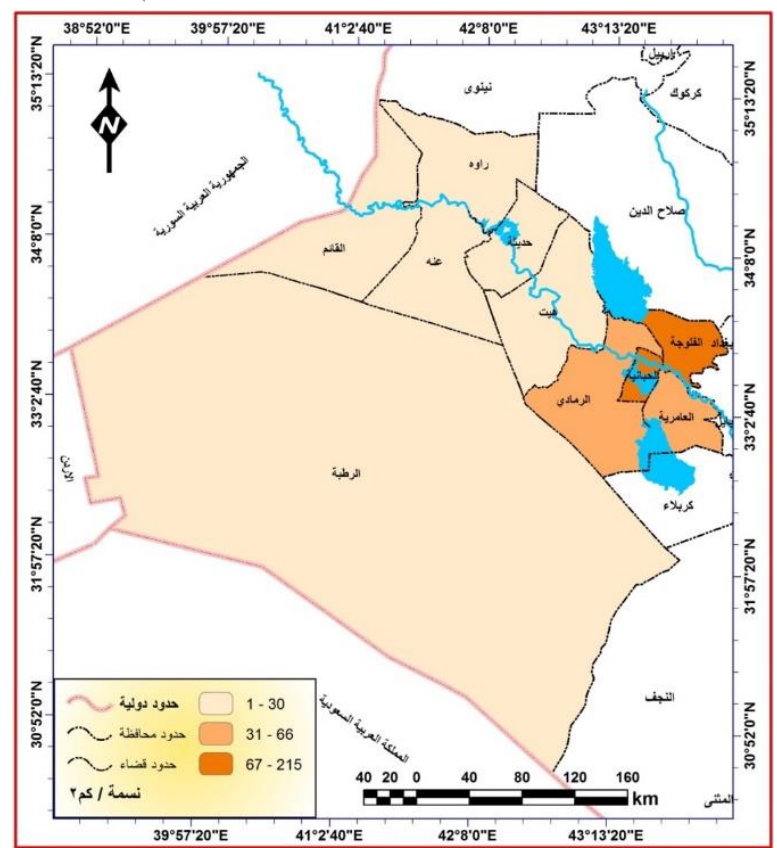

GIS 10.7 المصدر: بالاعتماد على جدول (4) وبرنامج نظم المعلومات الجغرافية

خريطة (12) التمثيل الحجمي والفئوي للسكان لأقضية محافظة الانبار لعام 2019

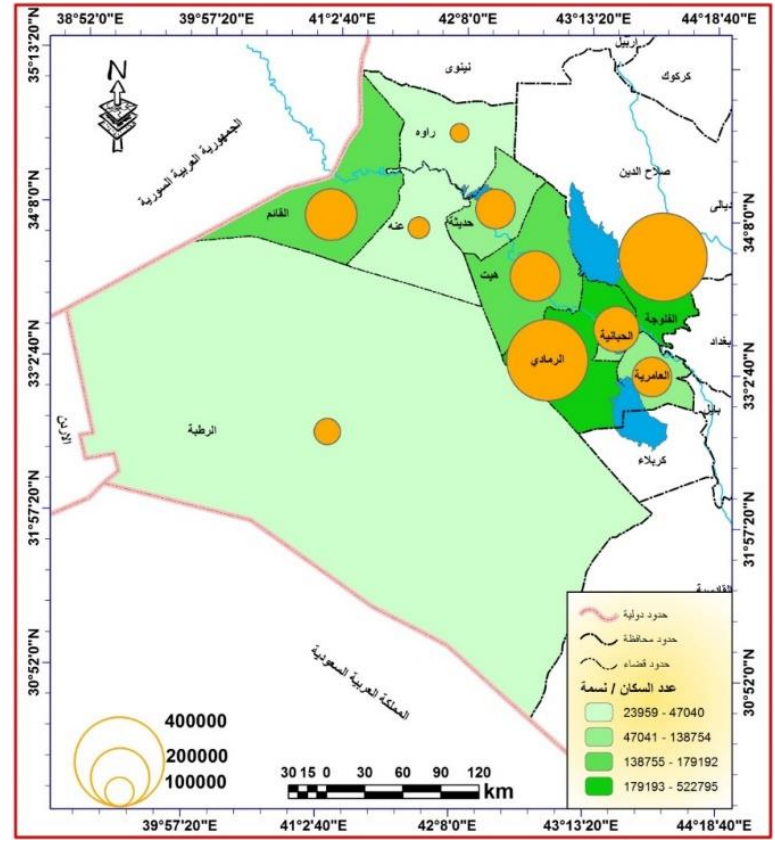

GIS 10.7 المصدر : بالاعتماد على جدول (4) وبرنامج نظم المعلومات الجغرافية 
من خلال المميزات التي يتيحها لنا نظم المعلومات الجغرافية الظاهرة في خريطة (12) اذ تم التمثيل بـ أي التوزيع الكمي المتعدد وهنا يقوم البرنامج بعمل تمييز او تباين للظاهر بطريقتين (Multiple Attributes)

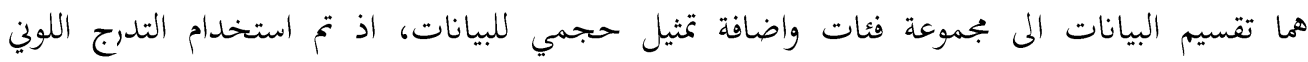
(Graduated symbols) من فئة الى التدرى في الطريقة الاولى في حجم الرمز (Graduated colors) (الذي هو الدائرة في هذه الخريطة) من قضاء الى اخر حسب عدد السكان في الطريقة الثانية، فنلاحظ ان

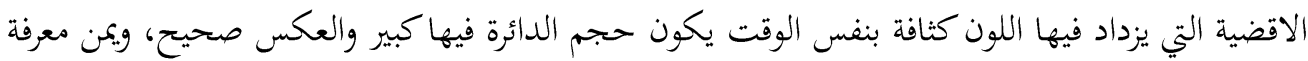
ذلك بوضوح من خلال ملاحظة مفتاح الخريطة.

النتائج:

1- لقد تم انتاج مجموعة من الخرائط الكمية الحناصة بتوزيع السكان حسب الاقضية في محافظة الانبار

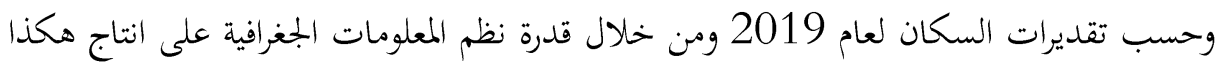
خرائط مقارنتا بالطرق التقليدية. 2- اتسم توزيع السكان في المحافظة بالتباين المكاني الكبير اذ جاء قضائي الفلوجة والرمادي بأكبر حجم سكاني وأكثر كثافة في حين جاء قضاء الرطبة باقل حجم سكاني واقل كثافة بسبب كبر مساحة القضاء. 3- الكفاءة العالية لتقنية وبرامج Arc GIs في مجال قياس المسافات والمساحات وتحديد المواقع الجغرافية وبدقة عالية في الترميز والتلوين وعمليات المعالجة الكارتوكرافية بشكل يستحيل تحقيقه بالطرق التقليدية. 4- أفضل طريقة للتوزيع الكمي على الخرائط لابد ان تكون على اساس الرسم الطبقات المساحية وتغذيته بالبيانات كي يقوم البرنامج بأسقاط الرمز بمكان مناسب لبقية الرموز ولا يقوم بأسقاط الرمز بمكان محدد في ما لو كانت الطبقات نقطية مثلا.

\section{التوصيات}

1- توزيع سكان المحافظة يحتاج ايضا الى بيان اسباب التوزيع واظهار دور العلاقات المكانية التي بتجيدها نظم المعلومات الجغرافية وعلاقة الارتباط وعلاقة المجاور الاقرب وغيرها من مزايا التحليل المكاني 


\title{
2- اعتماد نظم المعلومات الجغرافية وعلى نطاق واسع في الابحاث الجغرافية لما يوفر من دقة وسرعة في التحليلات المكانية وانتاج الخرائط.
}

3- الانتقال من الطرق التقليدية في التحليل والتمثيل الخرائطي المى الطرق الكمية المستخدمة في نظم المعلومات الجغرافية.

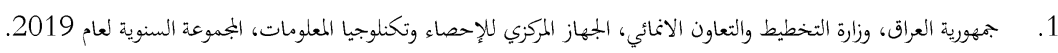

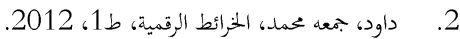

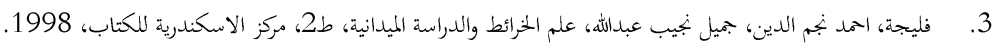

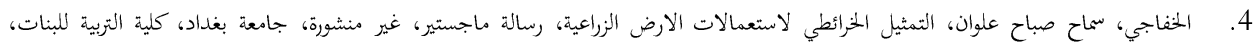

.2003

الذهبي، وسن كريم عبد الرضا، التمثيل الخرائطي للتوزيع المكاني لسكان محافظة بغداد لعام 1997 دراسة مقارنة بين الطرق التقليدية ونظم المعلومات

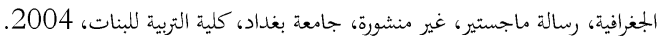

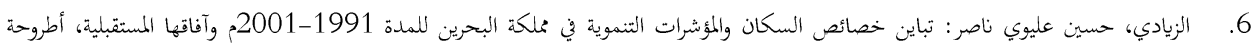

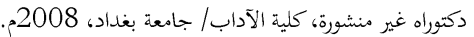

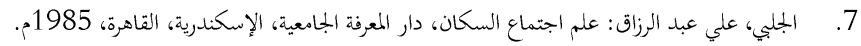

8.

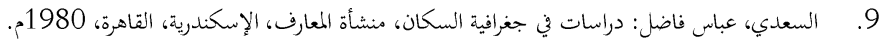

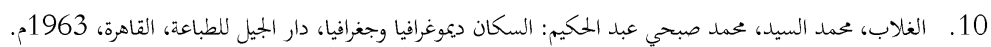

$$
\begin{aligned}
& \text { (1) الجهاز المركزي للإحصاء وتكنلوجيا المعلومات، المجموعة السنوية لعام 2019، جدول رقم 44، ص22. } \\
& \text { (2) داود، الخرائط الرقمية، ص372. }
\end{aligned}
$$

Campbell, map use and analysis, 3, edition, hill Newark, p. 17-172. (3)

$$
\begin{aligned}
& \text { (4) فليجة، علم الخرائط والدراسة الميدانية، ص182. } 172 \text { (18). }
\end{aligned}
$$

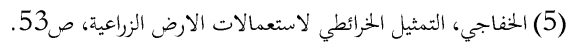

Jones, Christopher, geographical, information systems and computer cartography, London, Longman, 1998.p4. (6)

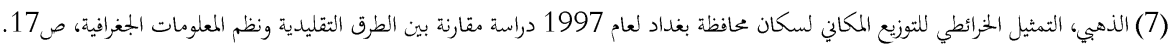

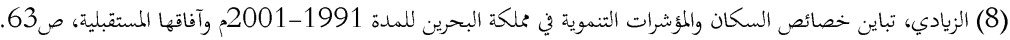

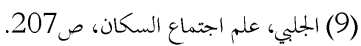

Henry M. Kendall, "Introduction to Geography", Harcourt, Newark, 1951, p: 317 (10)

$$
\begin{aligned}
& \text { 1) سهاونه، مبادئ الديموغرافيا، ص130. } \\
& \text { السعدي، دراسات في جغرافية السكان، ص23. } \\
& \text { الغلاب، السكان ديموغرافيا وجغرافيا، ص215. }
\end{aligned}
$$

